\title{
The Behavior of Masonry Walls with Reinforced Plaster Mortar
}

\author{
Hakan Basaran, ${ }^{1}$ Ali Demir, ${ }^{2}$ and Muhiddin Bagci ${ }^{2}$ \\ ${ }^{1}$ MOSB Vocational School, Celal Bayar University, Manisa 45020, Turkey \\ ${ }^{2}$ Department of Civil Engineering, Celal Bayar University, Muradiye, Manisa 45140, Turkey
}

Correspondence should be addressed to Hakan Basaran; hakan.basaran@cbu.edu.tr

Received 7 March 2013; Revised 27 April 2013; Accepted 29 April 2013

Academic Editor: Pavel Lejcek

Copyright (C) 2013 Hakan Basaran et al. This is an open access article distributed under the Creative Commons Attribution License, which permits unrestricted use, distribution, and reproduction in any medium, provided the original work is properly cited.

\begin{abstract}
The purpose of this study is the improvement of the behaviors of walls constructed with masonry bricks using reinforced plaster mortars. In this study, $400 \times 400 \times 100 \mathrm{~mm}$ sized walls were constructed using $1: 2$ scaled $100 \times 50 \times 30$ mm sized masonry bricks. The walls were plastered using normal and various proportions of polypropylene and steel fiber reinforced plaster mortars and were subjected to vertical loads at $30^{\circ}, 45^{\circ}, 60^{\circ}$, and $90^{\circ}$ angles. As a result of the experiments, attempts were made to present the strength, stiffness, and ductility of all of the walls. At the end of the study, an evaluation concerning failure envelope curve $(\sigma-\tau)$ obtained from test results according to plastered masonry walls types was performed.
\end{abstract}

\section{Introduction}

Masonry structures constructed without any technical assistance are about $40 \%-45 \%$ of the total structures found in Turkey. The vertical bearers of this type of structures are the walls. It was observed that the damages occurring on masonry structures are very large even if they are subjected to earthquakes of a small magnitude. A significant portion of the mortalities occurring during earthquakes results from such structures. Walls are not subjected only to vertical loads, but they are also subjected to horizontal loads such as wind and earthquakes. Biaxial loads occur on the walls due to these vertical and horizontal loads acting together. The performance of brick walls under double axis loads was investigated by various researchers, both theoretically and experimentally [1-3].

The wall is a composite material consisting of brick and mortar. The low shear and adherence strength of the mortar cause it to constitute a weak surface at joints. When a horizontal load is applied on a brick wall, the cracks generally occur in the mortar, and the segregations happen at the joining points of the brick and the mortar. Walls constructed using masonry bricks are a material that is resistant to pressure and weak under horizontal loads. Numerous studies were carried out in order to overcome this weakness. The studies generally aimed at increasing the adherence of the brick and the mortar. In these studies that were carried out, usually additives were included in the mortar in order to increase the tensile strength of the wall. The experimental studies carried out with the aim of increasing the strength, stiffness, and ductility of the masonry structures were compared with the numerical models that were created, in order to determine the levels of increase occurring in the strength, stiffness, and ductility of the masonry structures [4-9]. Various strengthening methods were developed in order to increase the strength of the masonry structures which were found to be inadequate against earthquakes. Significant improvements were obtained in the stiffness, strength, and ductility of buildings with masonry walls, by strengthening the brick surfaces with various materials (FRP, wires, fiber materials, wire mesh, reiforcements, steel and wood plates, and unused tires) [10$14]$.

In this study, an attempt was made to compare the brick walls plastered using normal, polypropylene, and steel fiber reinforced plaster mortars, in terms of stiffness, strength, and ductility. In addition, an evaluation concerning failure envelope curve $(\sigma-\tau)$ obtained from test results according to plastered masonry walls types was performed. 


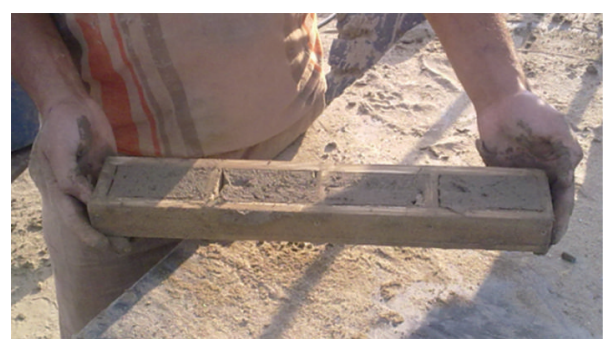

(a)

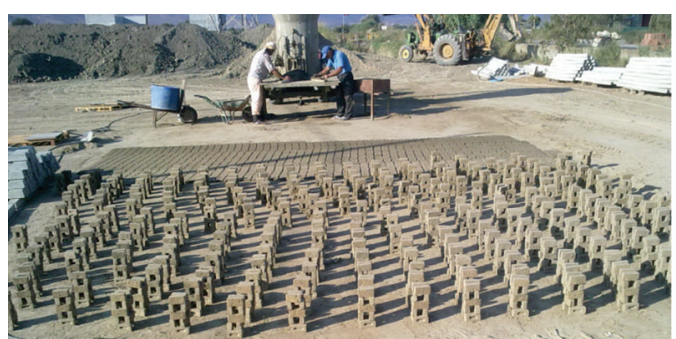

(b)

FIGURE 1: The masonry bricks dried under the sun.

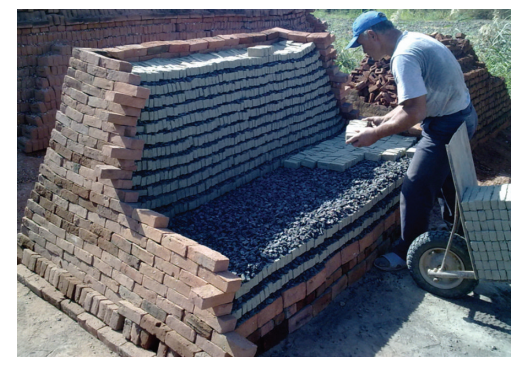

(a)

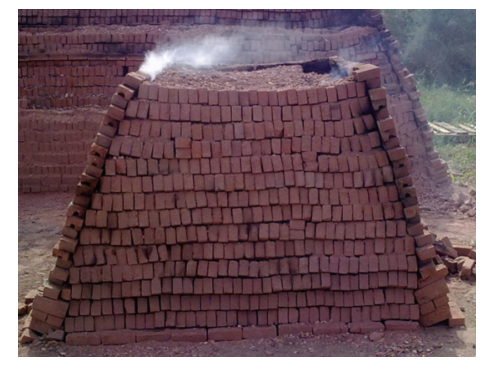

(b)

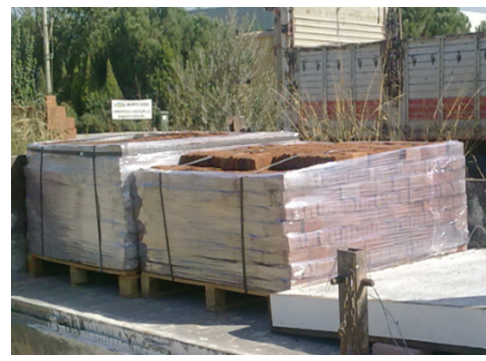

(c)

FIGURE 2: The masonry bricks ready to use and stacked with coal.

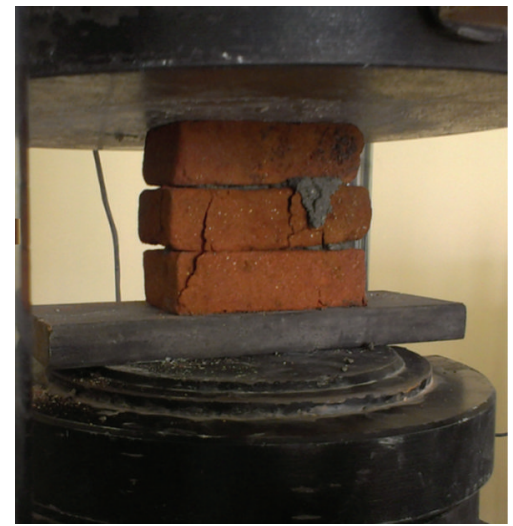

(a)

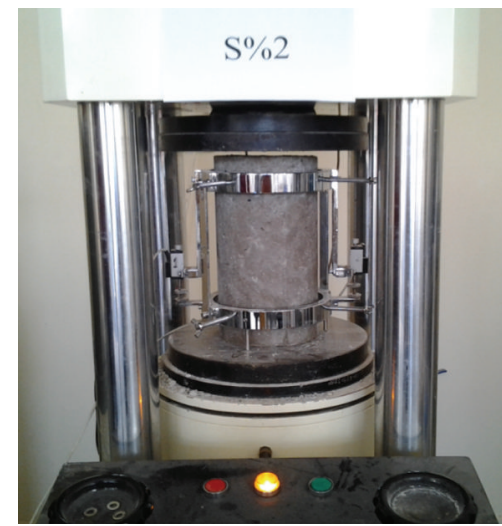

(b)

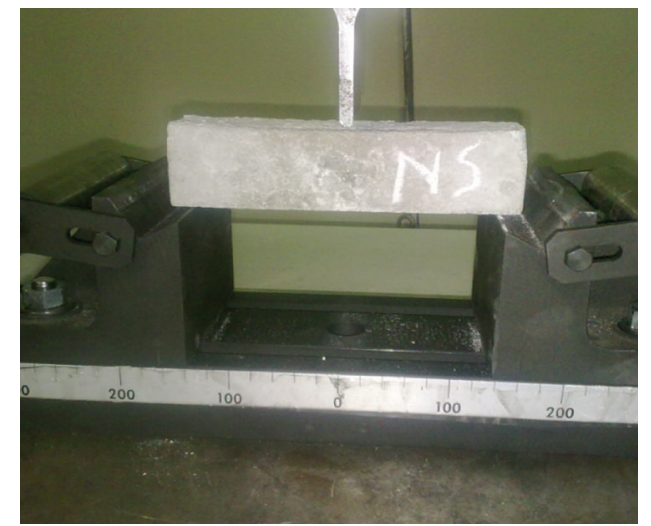

(c)

FIGURE 3: The experiments prepared of mechanical properties of bricks and mortar.

\section{Materials and Methods}

2.1. Materials. Experimental methods play an important role in the development of earthquake-resistant design. In most of the study, researchers using a full size or scaled models examine the behaviour of buildings under seismic effects. In preparation of the full scale experimental setups, the cost is very high and takes a long time. In this study, $400 \times 400 \times$ $100 \mathrm{~mm}$ sized walls were constructed using 1:2 scaled $100 \times$ $50 \times 30 \mathrm{~mm}$ sized masonry bricks. The standard test technique for the masonry-wall samples was used as recommended in TSE 771-1 [15]. The masonry brick moulds were prepared for the production of the bricks. The brick clay produced using clayed soil was poured into moulds and left in the sun to dry as shown in Figure 1.
The bricks that completely dried under the sun were stacked with coal placed between them and were ready to use following a brick burning procedure which lasted approximately 7 days as shown in Figure 2. The experiments which determine mechanical properties of bricks and mortars are shown in Figure 3. The number of samples prepared for each of brick and mortar is 3 .

The standard brick test technique for the samples prepared according to TSE 7720 [15] was used. For the bricks that were used in the experiments, the compressive strength value was 2,65 MPa, modulus of elasticity was $125 \mathrm{MPa}$, and tensile strength was $0,5 \mathrm{MPa}$. In the grout mortar used as binder, the sand: lime: cement: water ratio was 20/2/3,6/1,7. The standard mortar test technique for the samples prepared 


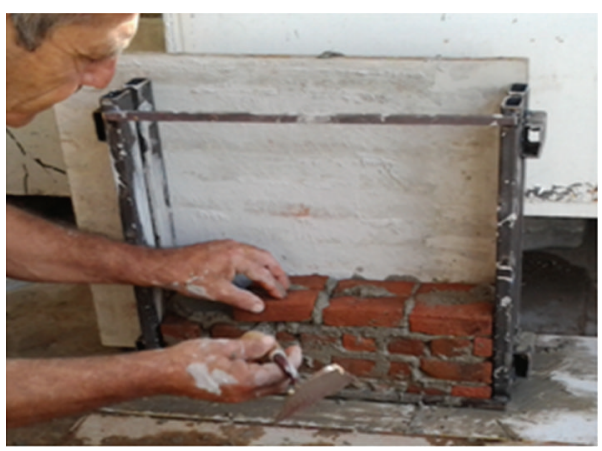

(a)

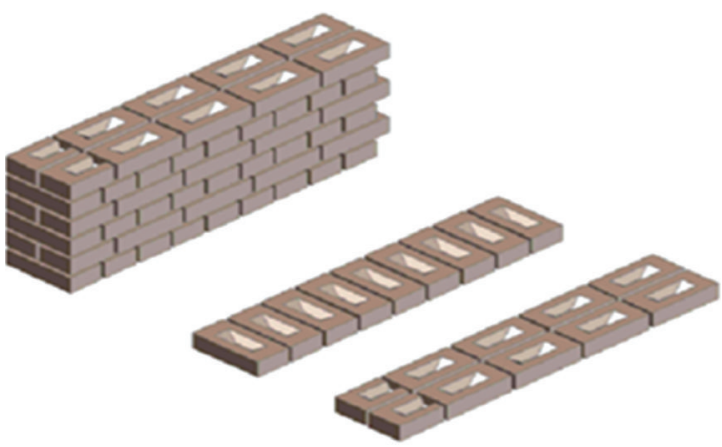

(b)

FIGURE 4: The wall samples prepared the dimensions $400 \times 400 \times 100 \mathrm{~mm}$.

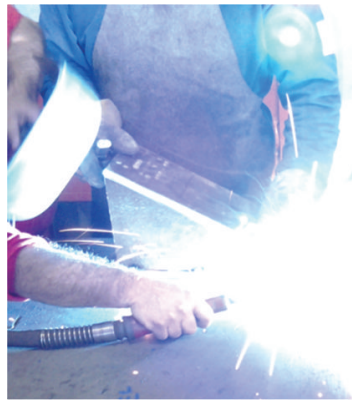

(a)
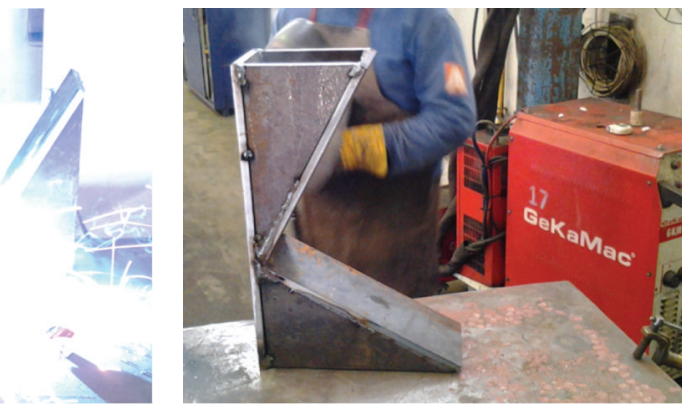

(b)

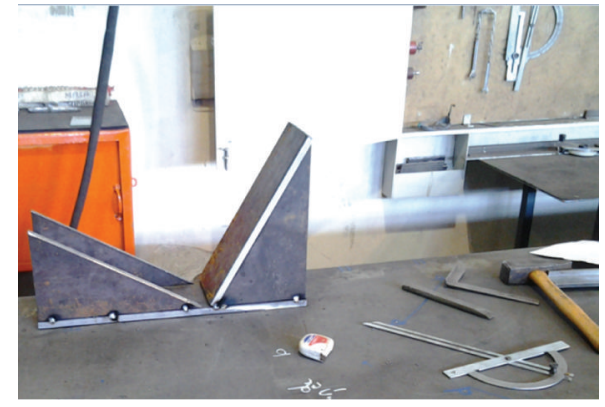

(c)

Figure 5: Upper and lower hoods.

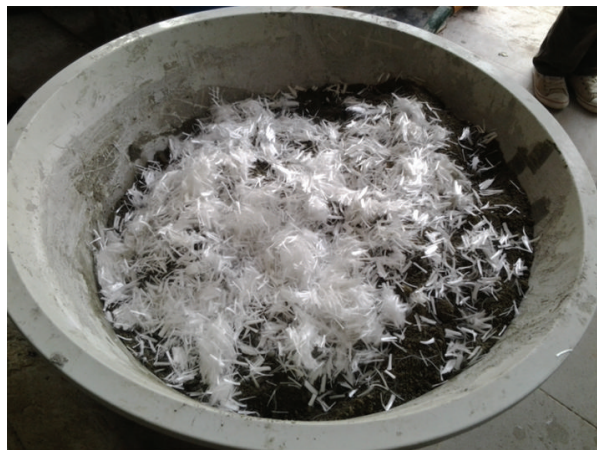

(a)

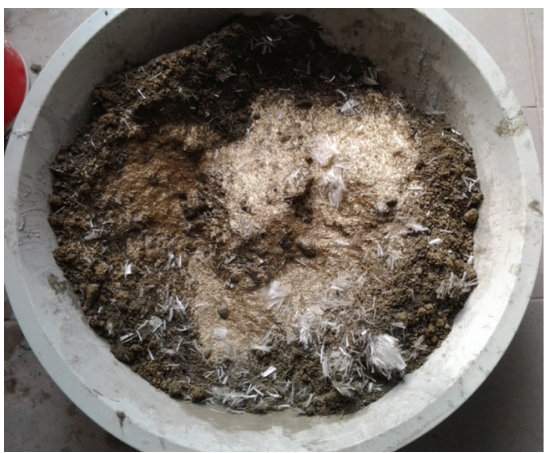

(b)

Figure 6: The polypropylene and steel fiber additives.

according to TSE 705 [15] was used. The compressive strength and modulus of elasticity values obtained for the grout mortar were 2,68 and $2100 \mathrm{MPa}$, respectively, and the tensile strength value obtained from the bending test was $0,325 \mathrm{MPa}$.

The numbers of plastered masonry walls types with normal, polypropylene, and steel fiber are six. Four specimens were considered for each kind of used plaster mortar. Total of 24 experiments were conducted on the masonry bricks plastered with normal, polypropylene and steel fiber reinforced plasters. The wall samples that were prepared had the dimensions $400 \times 100 \mathrm{~mm}$ as shown in Figure 4 . The horizontal and vertical jointing gap used between the walls was $10 \mathrm{~mm}$.
Upper and lower hoods were made in order to facilitate the transfer of the loads to be applied on the samples and to keep the samples in their planes as shown in Figure 5.

The masonry brick walls constructed were also plastered with polypropylene and steel fiber reinforced materials under its traditional application. Since the effect of the additive materials in the plastering applied was researched, the type of sand and cement used was kept fixed. The polypropylene and steel fiber additives added into the plaster mortar are shown in Figure 6.

In the reinforced plaster mortar, $2 \%$ and $3 \%$ polypropylene and $2 \%$ and $5 \%$ steel fiber were used. Normal plaster was denoted with $\mathrm{N}, 2 \%$ and $3 \%$ polypropylene added plaster 


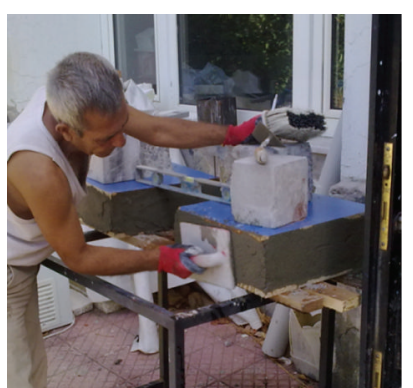

(a)

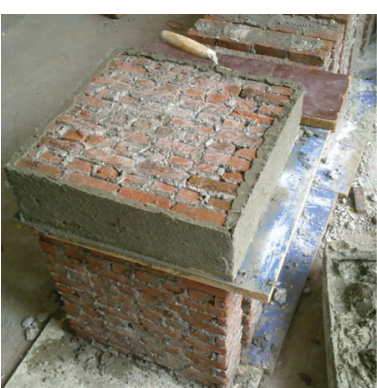

(b)

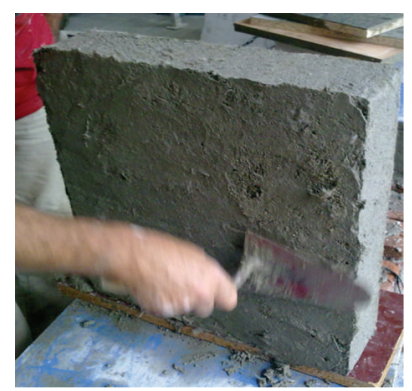

(c)

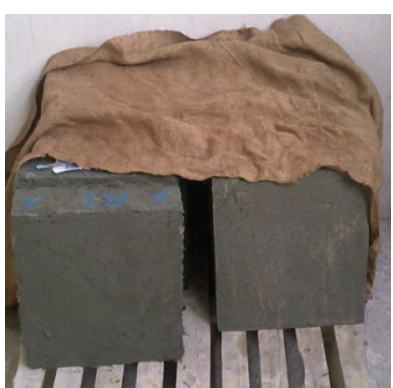

(d)

FIGURE 7: The masonry wall with reinforced plaster mortars.

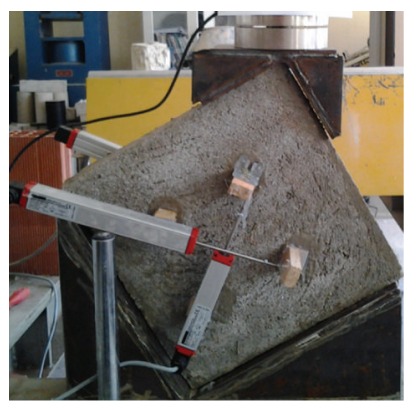

(a)

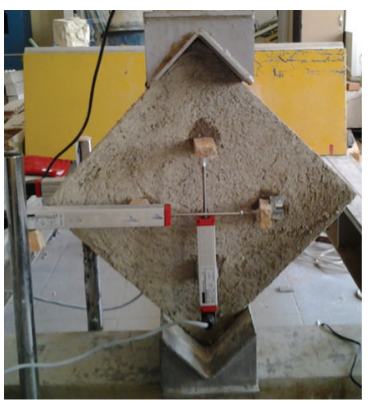

(b)

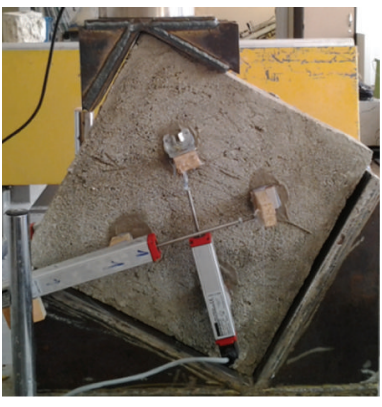

(c)

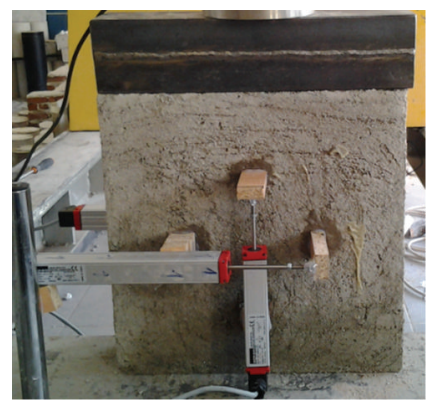

(d)

Figure 8: Experiments at $30^{\circ}, 45^{\circ}, 60^{\circ}$, and $90^{\circ}$ angles.

TABLE 1: The mechanical properties of the plaster material.

\begin{tabular}{lccc}
\hline Sample & $\begin{array}{c}\text { Compressive } \\
\text { strength } \\
(\mathrm{Mpa})\end{array}$ & $\begin{array}{c}\text { Tensile } \\
\text { strength } \\
(\mathrm{Mpa})\end{array}$ & $\begin{array}{c}\text { Modulus of } \\
\text { elasticity } \\
(\mathrm{MPa})\end{array}$ \\
\hline $\mathrm{N}$ & 2,68 & 0,325 & 2100 \\
P2 & 7,05 & 0,561 & 5189 \\
P3 & 8,95 & 0,573 & 9017 \\
S2 & 4,26 & 0,657 & 6650 \\
S5 & 4,82 & 0,867 & 10450 \\
P2S3 & 3,61 & 0,589 & 5534 \\
\hline
\end{tabular}

mortars with PS2 and PS3, respectively, 2\% and 5\% steel fiber added plaster mortar with S2 and S5, respectively, and the hybrid plaster composed of $2 \%$ polypropylene and $3 \%$ steel fiber was denoted using P2S3. The mechanical properties of the plaster material obtained from the experiments are shown in Table 1.

When P3 was used in hybrid plaster composite, workability was difficult. If S5 was used in hybrid plaster composite, plaster mortar was uncomfortable for human body. Therefore, $\mathrm{P} 2 \mathrm{~S} 3$ are considered as hybrid plaster composite type.

The maximum grain diameter of the sand used in the plaster mortars was $4 \mathrm{~mm}$. Portland cement (CemII-42,5) was used in the plaster mortars. The plaster was applied to firstly side edges of the walls. Later, the plasters were applied to the two opposite surfaces with a trowel. The walls were completely wrapped by plaster mortar. After the plaster mortars were applied, the samples were cured in the laboratory at
7 days, afterwards left in a dry environment for 3 days, and then tested in Figure 7.

2.2. Methods. In the experiments, the value of the applied load was measured using a load cell with $250 \mathrm{kN}$ capacity that was placed on the hydraulic jack. The vertical load was applied with hydraulic jack at $30^{\circ}, 45^{\circ}, 60^{\circ}$, and $90^{\circ}$ angles, as shown in Figure 8. The loads were applied constantly, with $0,1 \mathrm{~mm} / \mathrm{s}$ intervals.

Linear voltage displacement transducers (LVDT) were placed on the point of load application and the two opposite surfaces in order to determine the displacements. The values were read by the LVDT and were transferred to the computer through the data collection system and simultaneously recorded. The experiment setup and the system that was used to evaluate the readings obtained from the load cell and the LVDT are shown in Figure 9.

\section{Results and Discussions}

Twenty-four wall samples were subjected to vertical loading at $30^{\circ}, 45^{\circ}, 60^{\circ}$, and $90^{\circ}$ angles, and the maximum load, shear strength, stiffness, ductility and consumed energy levels were calculated for all samples.

These values obtained from reinforced plastered samples were compared with the values obtained from the reference samples as given in Tables 2-7. At the end of the experiments, the relationships between loads and displacements values 


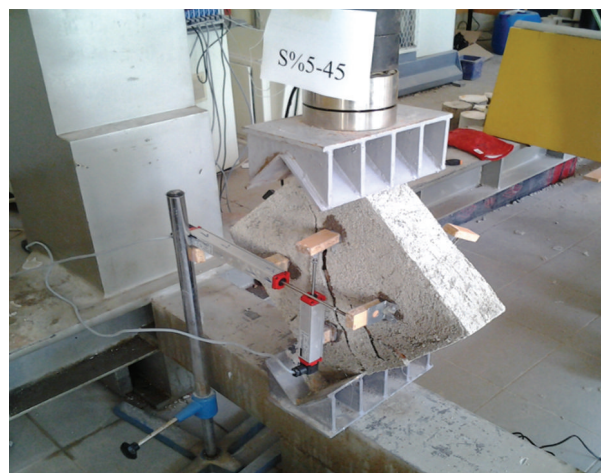

(a)

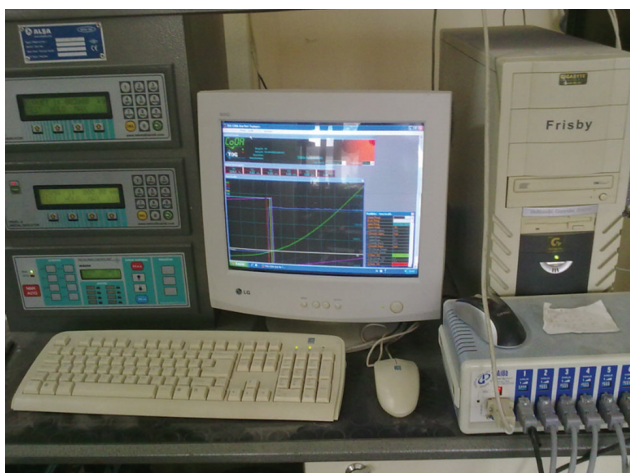

(b)

FIGURE 9: The experiment setup and data collection system.

TABLE 2: The maximum load values and the load capacity of the walls.

\begin{tabular}{|c|c|c|c|c|c|c|c|}
\hline \multirow{2}{*}{ Angles } & \multirow{2}{*}{ Values } & \multicolumn{6}{|c|}{ The wall samples with reinforced plaster mortar } \\
\hline & & $\mathrm{N}$ & $\mathrm{P} 2$ & P3 & S2 & S5 & $\mathrm{P} 2 \mathrm{~S} 3$ \\
\hline \multirow{2}{*}{$30^{\circ}$} & The maximum load $(\mathrm{N})$ & 36033,5 & 50357,4 & 76961,8 & 60084,8 & 66900,0 & 58606,6 \\
\hline & The rates of in the load capacity & 1,00 & 1,40 & 2,14 & 1,67 & 1,86 & 1,63 \\
\hline \multirow{2}{*}{$45^{\circ}$} & The maximum load $(\mathrm{N})$ & 64346,0 & 80722,2 & 133952,3 & 97453,0 & 99606,7 & 93570,8 \\
\hline & The rates of in the load capacity & 1,00 & 1,25 & 2,08 & 1,51 & 1,55 & 1,45 \\
\hline \multirow{2}{*}{$60^{\circ}$} & The maximum load $(\mathrm{N})$ & 84886,5 & 123377,7 & 161036,1 & 129054,8 & 127649,8 & 125806,1 \\
\hline & The rates of in the load capacity & 1,00 & 1,45 & 1,90 & 1,52 & 1,50 & 1,48 \\
\hline \multirow{2}{*}{$90^{\circ}$} & The maximum load $(\mathrm{N})$ & 100417,5 & 170565,2 & 215145 & 162849,5 & 144047,6 & 139507,5 \\
\hline & The rates of in the load capacity & 1,00 & 1,70 & 2,14 & 1,62 & 1,43 & 1,39 \\
\hline
\end{tabular}

TABLE 3: The shear strengths of the walls.

\begin{tabular}{|c|c|c|c|c|c|c|c|}
\hline \multirow[t]{2}{*}{ Angles } & \multirow[t]{2}{*}{ Values } & \multicolumn{6}{|c|}{$\begin{array}{l}\text { The wall samples with reinforced } \\
\text { plaster mortar }\end{array}$} \\
\hline & & $\mathrm{N}$ & $\mathrm{P} 2$ & P3 & $\mathrm{S} 2$ & S5 & $\mathrm{P} 2 \mathrm{~S} 3$ \\
\hline \multirow{2}{*}{$30^{\circ}$} & The shear strength & 0,780 & 1,090 & 1,666 & 1,301 & 1,448 & 1,269 \\
\hline & $\begin{array}{l}\text { The rates of shear } \\
\text { strength }\end{array}$ & 1,00 & 1,40 & 2,14 & 1,67 & 1,86 & 1,63 \\
\hline \multirow{2}{*}{$45^{\circ}$} & The shear strength & 1,137 & 1,427 & 2,368 & 1,727 & 1,761 & 1,654 \\
\hline & $\begin{array}{l}\text { The rates of shear } \\
\text { strength }\end{array}$ & 1,00 & 1,25 & 2,08 & 1,52 & 1,55 & 1,45 \\
\hline \multirow{2}{*}{$60^{\circ}$} & The shear strength & 1,061 & 1,542 & 2,013 & 1,613 & 1,596 & 1,573 \\
\hline & $\begin{array}{l}\text { The rates of shear } \\
\text { strength }\end{array}$ & 1,00 & 1,45 & 1,90 & 1,52 & 1,50 & 1,48 \\
\hline
\end{tabular}

transferred to the computer as explained in Section 2.2 were drawn with excel program as shown in Figure 10.

At the end of the experiments, it was observed that the reinforced plaster applications were very effective on the load carrying capacity of the walls. The maximum load values which can be seen in the curves in Figure 10 are shown in Table 2. In Table 2, the rates of increase in the load capacity of the walls plastered with reinforced plaster mortars and the walls with normal plaster mortar which were used as reference samples are compared. When normal plastered brick walls are taken as reference samples, the greatest increase in load carrying capacity was 2,14 times, in the P3 sample for experiments carried out under $30^{\circ}, 2,08$
TABLE 4: The stiffness values of the wall samples.

\begin{tabular}{|c|c|c|c|c|c|c|c|}
\hline \multirow[t]{2}{*}{ Angles } & \multirow[t]{2}{*}{ Values } & \multicolumn{6}{|c|}{$\begin{array}{l}\text { The wall samples with reinforced plaster } \\
\text { mortar }\end{array}$} \\
\hline & & $\mathrm{N}$ & P2 & P3 & S2 & S5 & $\mathrm{P} 2 \mathrm{~S} 3$ \\
\hline \multirow{2}{*}{$30^{\circ}$} & The stiffness & 141 & 86 & 100 & 114 & 157 & 100 \\
\hline & The stiffness ratio & 1,00 & 0,61 & 0,71 & 0,81 & 1,11 & 0,71 \\
\hline \multirow{2}{*}{$45^{\circ}$} & The stiffness & 133 & 87 & 167 & 115 & 139 & 145 \\
\hline & The stiffness ratio & 1,00 & 0,65 & 1,26 & 0,86 & 1,05 & 1,09 \\
\hline \multirow{2}{*}{$60^{\circ}$} & The stiffness & 147 & 178 & 166 & 149 & 188 & 145 \\
\hline & The stiffness ratio & 1,00 & 1,21 & 1,13 & 1,01 & 1,28 & 0,99 \\
\hline \multirow{2}{*}{$90^{\circ}$} & The stiffness & 149 & 223 & 238 & 231 & 347 & 153 \\
\hline & The stiffness ratio & 1,00 & 1,50 & 1,60 & 1,55 & 2,33 & 1,03 \\
\hline
\end{tabular}

times in the P3 sample under $45^{\circ}, 1,9$ times in the $\mathrm{P} 3$ sample under $60^{\circ}$, and 2,14 times in the P3 sample under $90^{\circ}$.

The shear strength values of the samples were obtained with the help of (1), using the maximum load values obtained from the experiments as follows:

$$
\tau=\frac{\cos \alpha \times p}{h \times t} .
$$

Here, $\cos \alpha \times p$ is defined as forces parallel to the horizontal mortar, $h$ as width of the wall, and $t$ as thickness of wall. The shear strength values obtained using (1) and the shear strength ratios obtained according to the reference sample are shown in Table 3. According to the results of 
TABLE 5: The deformation ability values of the samples.

\begin{tabular}{ccccccc}
\hline Angles & Samples & $\Delta_{P_{\max }}$ & $\Delta_{0,85 P_{\max }}$ & $\Delta_{0,5 P_{\max }}$ & $\mu_{0,85}$ & $\mu_{0,5}$ \\
\hline \multirow{6}{*}{$30^{\circ}$} & $\mathrm{N}$ & 2,589 & 2,863 & 3,301 & 1,106 & 1,275 \\
& P2 & 5,925 & 6,826 & 7,426 & 1,152 & 1,253 \\
& P3 & 8,008 & 9,963 & 11,629 & 1,244 & 1,452 \\
& S2 & 5,606 & 6,182 & 8,259 & 1,103 & 1,473 \\
& S5 & 4,504 & 5,270 & 5,625 & 1,170 & 1,249 \\
& P2S3 & 5,874 & 6,873 & 7,872 & 1,170 & 1,340 \\
\hline \multirow{6}{*}{$45^{\circ}$} & N & 5,477 & 6,329 & 7,591 & 1,156 & 1,386 \\
& P2 & 9,466 & 10,300 & 10,919 & 1,088 & 1,153 \\
& P3 & 8,566 & 10,177 & 15,698 & 1,188 & 1,833 \\
& S2 & 8,799 & 10,447 & 10,992 & 1,187 & 1,249 \\
& S5 & 7,536 & 8,511 & 9,426 & 1,129 & 1,251 \\
& P2S3 & 6,783 & 8,149 & 9,987 & 1,201 & 1,472 \\
\hline \multirow{6}{*}{$60^{\circ}$} & N & 5,956 & 6,348 & 7,095 & 1,066 & 1,191 \\
& P2 & 7,175 & 8,713 & 11,875 & 1,214 & 1,655 \\
& P3 & 10,055 & 13,275 & 20,153 & 1,320 & 2,004 \\
& S2 & 8,688 & 10,612 & 11,789 & 1,221 & 1,357 \\
& S5 & 7,273 & 8,082 & 9,387 & 1,111 & 1,291 \\
& P2S3 & 9,019 & 11,034 & 13,538 & 1,223 & 1,501 \\
\hline \multirow{6}{*}{$90^{\circ}$} & N & 7,116 & 8,501 & 11,050 & 1,195 & 1,553 \\
& P2 & 8,443 & 9,473 & 11,439 & 1,122 & 1,355 \\
& P3 & 10,300 & 12,379 & 19,084 & 1,202 & 1,853 \\
& S2 & 7,367 & 8,427 & 12,809 & 1,144 & 1,739 \\
& P2S3 & 4,320 & 6,090 & 9,630 & 1,410 & 2,229 \\
& 9,369 & 10,668 & 13,756 & 1,139 & 1,468 \\
\hline & & & & & &
\end{tabular}

TABLE 6: The amounts of energy consumed by the samples.

\begin{tabular}{|c|c|c|c|c|c|}
\hline Angles & Samples & $\mathrm{A}_{0,85 P_{\max }}$ & $\mathrm{A}_{0,5 P_{\max }}$ & A.R. ${ }_{0,85 P_{\max }}$ & A.R. ${ }_{0,5 P_{\max }}$ \\
\hline \multirow{6}{*}{$30^{\circ}$} & $\mathrm{N}$ & 57741 & 67999 & 1,00 & 1,00 \\
\hline & $\mathrm{P} 2$ & 195638 & 214641 & 3,39 & 3,16 \\
\hline & P3 & 478218 & 564022 & 8,28 & 8,29 \\
\hline & S2 & 187478 & 271421 & 3,25 & 3,99 \\
\hline & S5 & 211753 & 229225 & 3,67 & 3,37 \\
\hline & $\mathrm{P} 2 \mathrm{~S} 3$ & 230374 & 271187 & 3,99 & 3,99 \\
\hline \multirow{6}{*}{$45^{\circ}$} & $\mathrm{N}$ & 249752 & 303996 & 1,00 & 1,00 \\
\hline & P2 & 454189 & 488575 & 1,82 & 1,61 \\
\hline & P3 & 788918 & 1297555 & 3,16 & 4,27 \\
\hline & S2 & 707924 & 746789 & 2,83 & 2,46 \\
\hline & S5 & 542823 & 604196 & 2,17 & 1,99 \\
\hline & $\mathrm{P} 2 \mathrm{~S} 3$ & 466250 & 577813 & 1,87 & 1,90 \\
\hline \multirow{6}{*}{$60^{\circ}$} & $\mathrm{N}$ & 293217 & 338390 & 1,00 & 1,00 \\
\hline & P2 & 666364 & 944942 & 2,27 & 2,79 \\
\hline & P3 & 1330731 & 2108299 & 4,54 & 6,23 \\
\hline & S2 & 860024 & 958548 & 2,93 & 2,83 \\
\hline & S5 & 612403 & 722778 & 2,09 & 2,14 \\
\hline & $\mathrm{P} 2 \mathrm{~S} 3$ & 863767 & 1078276 & 2,95 & 3,19 \\
\hline \multirow{6}{*}{$90^{\circ}$} & $\mathrm{N}$ & 498121 & 669666 & 1,00 & 1,00 \\
\hline & P2 & 862267 & 1072263 & 1,73 & 1,60 \\
\hline & P3 & 1513594 & 2578503 & 3,04 & 3,85 \\
\hline & S2 & 827070 & 1336736 & 1,66 & 2,00 \\
\hline & S5 & 562622 & 901649 & 1,13 & 1,35 \\
\hline & $\mathrm{P} 2 \mathrm{~S} 3$ & 976993 & 1259821 & 1,96 & 1,88 \\
\hline
\end{tabular}

TABLE 7: The shear stress obtained according to the wall types.

\begin{tabular}{lc}
\hline Samples & The shear stress equation \\
\hline N & $\tau=0,546+0,520 \sigma$ \\
P2 & $\tau=0,825+0,422 \sigma$ \\
P3 & $\tau=1,186+0,499 \sigma$ \\
S2 & $\tau=0,975+0,434 \sigma$ \\
S5 & $\tau=1,166+0,338 \sigma$ \\
P2S3 & $\tau=0,963+0,418 \sigma$ \\
\hline
\end{tabular}

the experiment, it was seen that the reinforced plasters had a significant effect on the shear strengths of the wall. In Table 3, the shear strength and shear strength rate of the walls plastered with reinforced plaster mortars and the walls with normal plaster mortar which were used as reference samples are compared. When normal plastered brick walls are taken as reference samples, the greatest increase in shear strength was 2,14 times, in the P3 sample for experiments carried out under $30^{\circ}, 2,08$ times in the P3 sample under $45^{\circ}$, and 1,9 times in the P3 sample under $60^{\circ}$. The shear strength value in (1) is proportional to the load carrying capacity values. Therefore, the shear strength rates are similar to the load carrying capacity increase rate.

The stiffness values of the wall samples were calculated as the slope of the region where the load-displacement curve was linear. The results obtained are shown in Table 4.

When the stiffness values of the samples with reinforced, plaster mortars were compared with the values of the reference samples, and a significant difference between the stiffness values was observed. Therefore, it can be said that the reinforced plaster is effective on the stiffness of the samples. It is thought that creating a good adherence surface between the wall and the reinforced plaster has a positive effect on the initial stiffness values of the samples in reinforced plaster applications. The deformation ability of the wall samples were calculated using (2) as follows:

$$
\begin{gathered}
\mu_{0.85}=\frac{\Delta_{0,85 P_{\max }}}{\Delta_{P_{\max }}} \\
\mu_{0.5}=\frac{\Delta_{0,5 P_{\max }}}{\Delta_{P_{\max }}} .
\end{gathered}
$$

In the equations, $\mu_{0.85}$ and $\mu_{0.50}$ represent the deformation ability, and $\Delta_{\left(0,85 P_{\max }\right)}$ and $\Delta_{\left(0,50 P_{\max }\right)}$ represent the vertical displacement values corresponding to the 0,85 and 0,50 levels of the maximum load on the decreasing arm in the load-displacement curve of the relevant sample, respectively. In Figure 11 and Table 5, values related to the deformation ability of the samples are given. When the results obtained from Table 5 are examined, it was seen that the reinforced plaster application increased the samples' ability of deformation. The reinforced plaster mortars increased the deformation ability of the samples and created a covering effect on the samples by not leaving the samples during the experiment. Thus, rupture of the samples was prevented and ductile behavior was obtained. This effect increases especially in the polypropylene fiber samples. In polypropylene additive samples, after the mortar and brick 

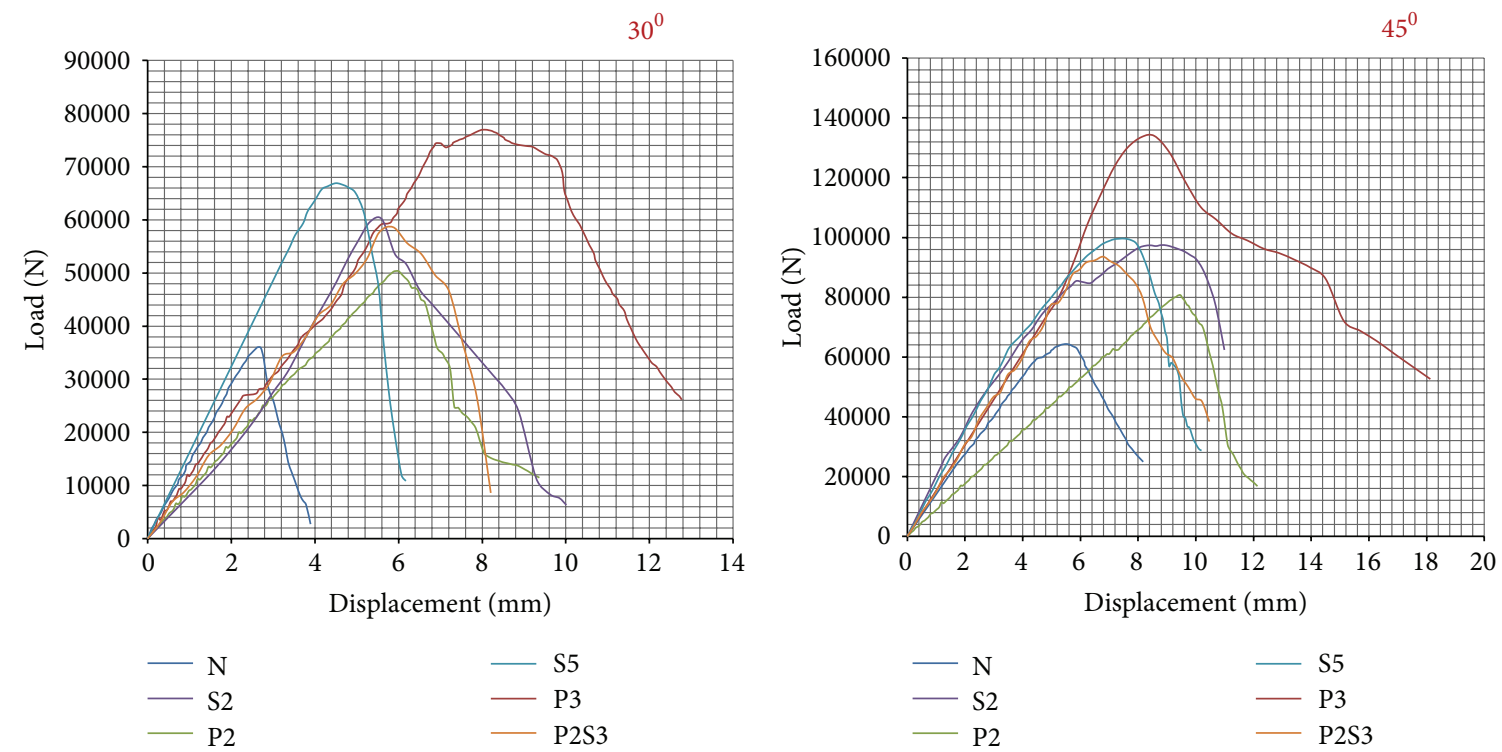

(a)

$60^{0}$

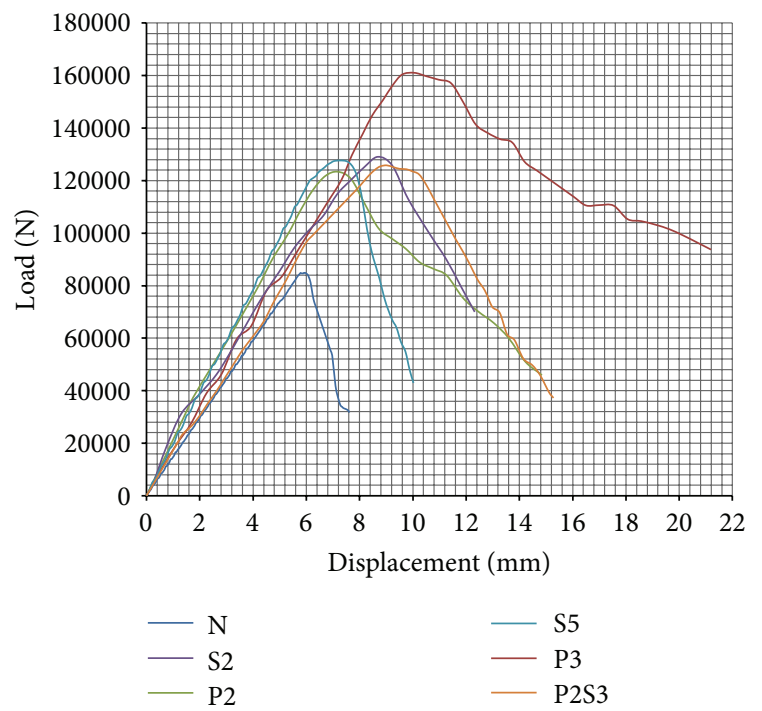

(c)

(b)

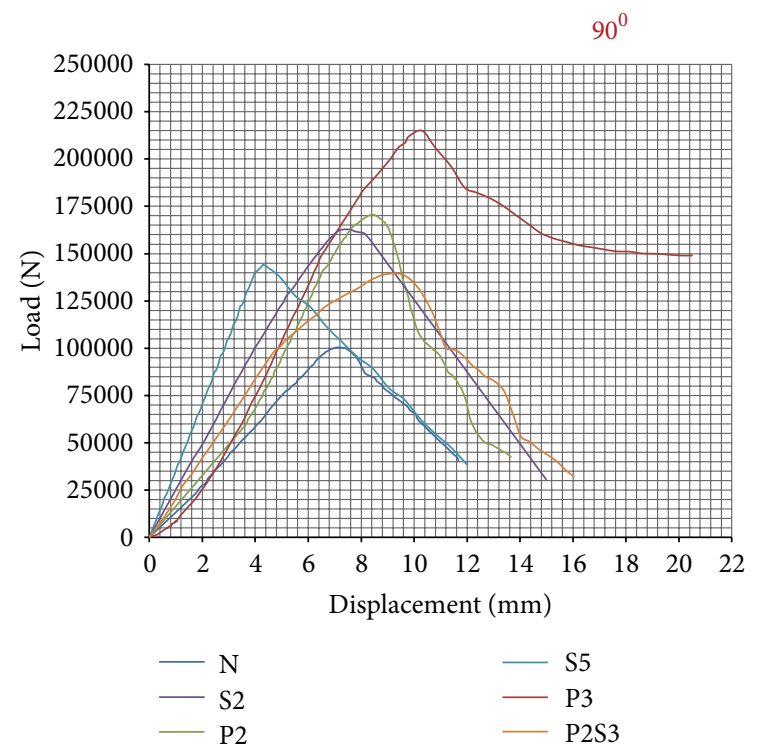

(d)

FIGURE 10: The relationships between loads and displacements.

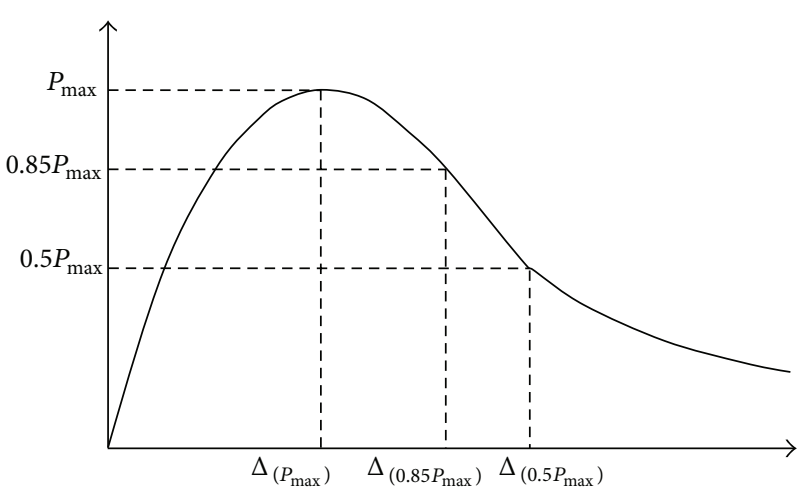

FIGURE 11: The deformation ability of the samples. samples are ruptured in the inner structure, the polypropylene fiber plaster crust swells and takes damage in Figure 12.

The highest deformation ability is observed in polypropylene fibered and then the steel fibered walls. The normal plastered samples have shown a lesser deformation ability compared to the reinforced plasters. The amounts of energy consumed by the samples during the experiment were calculated using the area below the load-displacement curves of the samples. Area values for the wall samples used in the study are given in Table 6. In the area calculation, the areas under the parts reaching the 0,85 and 0,50 levels of the maximum load level on the decreasing arm of the loaddisplacement curve were taken into consideration. In Table 6, the values belonging to the reinforced samples are given by 


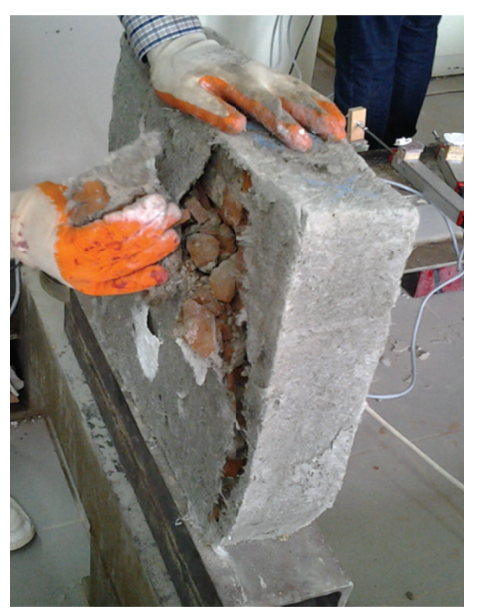

(a)

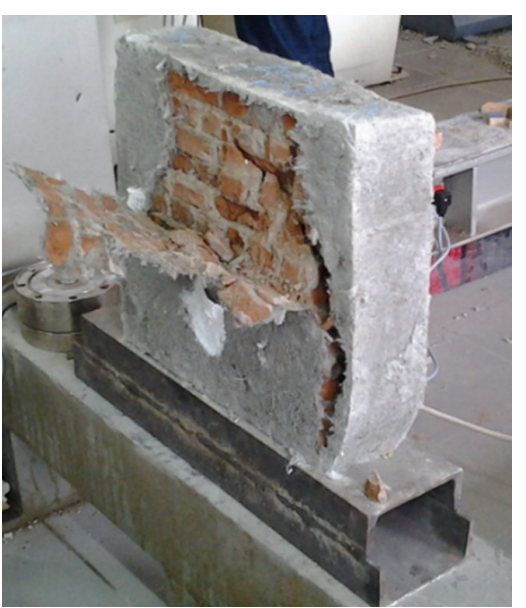

(b)

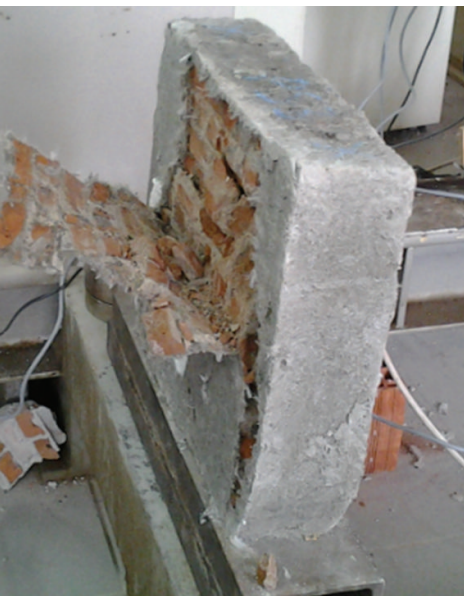

(c)

FIGURE 12: The polypropylene fiber plaster sample failure.

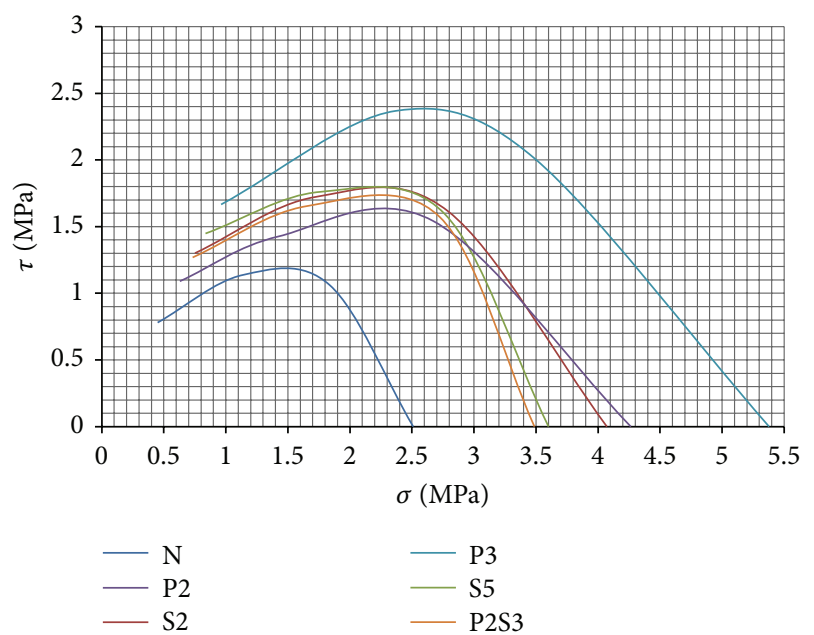

FIGURE 13: $\sigma$ and $\tau$ values obtained from the maximum loads.

proportioning to the average of the values belonging to the reference samples. When normal plastered brick walls are taken as reference samples, the rate of increase in the area (A.R.) below the part until the 0,85 level of the maximum load level was 8,28 times for the P3 sample in the experiment carried out at $30^{\circ}$ angle, 3,16 times for the P3 sample at $45^{\circ}$ angle, 4,54 times for the $\mathrm{P} 3$ sample at $60^{\circ}$ angle, and 3,04 times for the $\mathrm{P} 3$ sample at $90^{\circ}$ angle. The rate of increase in the area below the part until the 0,50 level of the maximum load level was 8,29 times for the P3 sample in the experiment carried out at $30^{\circ}$ angle, 4,27 times for the P3 sample at $45^{\circ}$ angle, 6,23 times for the $\mathrm{P} 3$ sample at $60^{\circ}$ angle, and 3,85 times for the $\mathrm{P} 3$ sample at $90^{\circ}$ angle. The highest energy consumption was observed in polypropylene fibered walls, followed by steel fibered walls.

The envelope curves drawn using the $\sigma$ and $\tau$ values obtained from the maximum loads following the $30^{\circ}, 45^{\circ}$, and $60^{\circ}$ diagonal and $90^{\circ}$ distributed force tests carried out on the 24 wall samples plastered with normal, polypropylene, and steel fiber reinforced mortars are shown in Figure 13.
The load consumption in the wall samples occurs in the form of shear and pressure failure, according to the vertical and horizontal components of the load applied. In the case of shear failure, the strength equation is expressed as follows:

$$
\tau=\tau_{\mathrm{o}}+\mu \sigma
$$

Here, $\mu$ is defined as the coefficient of friction between the brick and the mortar, $\tau$ as the tension during the shear failure, and $\tau_{\mathrm{o}}$ as basic shear adherence tension. The shear stress obtained from Figure 13 according to the wall types is shown in Table 7.

In the shear failure equations obtained from Table 7, the smallest friction force was 0,338 in S5 sample and the largest was 0,520 in $\mathrm{N}$ sample. The largest adherence was 1,186 in P3 sample and the smallest adherence was 0,546 in $\mathrm{N}$ sample.

\section{Conclusions}

In this study, 24 wall samples $400 \times 400 \times 100 \mathrm{~mm}$ sized were constructed using $1: 2$ scaled $100 \times 50 \times 30 \mathrm{~mm}$ sized masonry bricks. The walls were plastered using normal, polypropylene, and steel fiber reinforced plaster mortars and were exposed to vertical loads at various angles. In the tests carried out, significant increases in the load carrying capacities of the samples produced using reinforced plasters were obtained. According to the test results, it was observed that the reinforced plaster application was very effective on the shear strengths of the walls. The reinforced plasters significantly increase the stiffness of the walls. It is thought that the increase observed in the initial rigidities in the reinforced plaster applications is due to a good adherence surface between the wall and the reinforced plaster. Through the reinforced plaster application, deformation ability of the samples increased. The reinforced plasters did not peel completely from the surface throughout the experiment and created a covering effect and increased the deformation ability of the walls. Thus, the rupturing of the samples was prevented and ductile behavior was obtained. The highest energy consumption was observed in the polypropylene fibered walls and then the steel fibered walls. 
In the envelope curves drawn following the experiment, using the $\sigma$ and $\tau$ values obtained from the maximum loads, it was observed that the highest adherence was obtained from polypropylene reinforced plasters.

\section{Acknowledgment}

The research described here was supported by the Scientific Research Project Commission of Celal Bayar University (Project no. 2012-47, 2012-98).

\section{References}

[1] M. Begimgil, "The effect of additives on the shear strength of brick masonry wall under biaxial loading," in Proceedings of the Asia-Pasific Conference on Masonry, pp. 21-25, Singapore, 1991.

[2] M. Kamanl, M. S. Donduren, M. T. Cogurcu, and M. Altın, "Experimental study of some masonry-wall coursework material types under horizontal loads and their comparison," Materials and Technology, vol. 45, no. 1, pp. 3-11, 2011.

[3] F. Y. Yokel and S. G. Fattal, "Failure hypothesis for masonry shear walls," Journal of the Structural Division, vol. 102, no. 3, pp. 515-532, 1976.

[4] M. Corradi, A. Borri, and A. Vignoli, "Experimental study on the determination of strength of masonry walls," Construction and Building Materials, vol. 17, no. 5, pp. 325-337, 2003.

[5] G. V. Guinea, G. Hussein, M. Elices, and J. Planas, "Micromechanical modeling of brick-masonry fracture," Cement and Concrete Research, vol. 30, no. 5, pp. 731-737, 2000.

[6] P. Laurence and J. Rots, "Multi surface interface model for analysis of masonry structures," Journal of Engineering Mechanical, vol. 123, no. 7, pp. 660-668, 1997.

[7] J. S. Lee, G. N. Pande, J. Middleton, and B. Kralj, "Numerical modelling of brick masonry panels subject to lateral loadings," Computers and Structures, vol. 61, no. 4, pp. 735-745, 1996.

[8] J. Lopez, S. Oller, E. Oñate, and J. Lubliner, "A homogeneous constitutive model for masonry," International Journal for Numerical Methods in Engineering, vol. 46, no. 10, pp. 1651-1671, 1999.

[9] S. Marfia and E. Sacco, "Modeling of reinforced masonry elements," International Journal of Solids and Structures, vol. 38, no. 24-25, pp. 4177-4198, 2001.

[10] M. R. Ehsani, H. Saadatmanesh, and A. Al-Saidy, "Shear behavior of URM retrofitted with FRP overlays," Journal of Composites for Construction, vol. 1, no. 1, pp. 17-25, 1997.

[11] H. Kolsch, "Carbon fiber cement matrix (CFCM) overlay system for masonry strengthening," Journal of Composites for Construction, vol. 2, no. 2, pp. 105-109, 1998.

[12] T. D. Krevaikas and T. C. Triantafillou, "Computer-aided strengthening of masonry walls using fibre-reinforced polymer strips," Materials and Structures, vol. 38, no. 275, pp. 93-98, 2005.

[13] T. Stratford, G. Pascale, O. Manfroni, and B. Bonfiglioli, "Shear strengthening masonry panels with sheet glass-fiber reinforced polymer," Journal of Composites for Construction, vol. 8, no. 5, pp. 434-443, 2004.

[14] M. R. Valluzzi, L. Binda, and C. Modena, "Mechanical behaviour of historic masonry structures strengthened by bed joints structural repointing," Construction and Building Materials, vol. 19, no. 1, pp. 63-73, 2005.

[15] Turkish Standard Institute, 2000. 

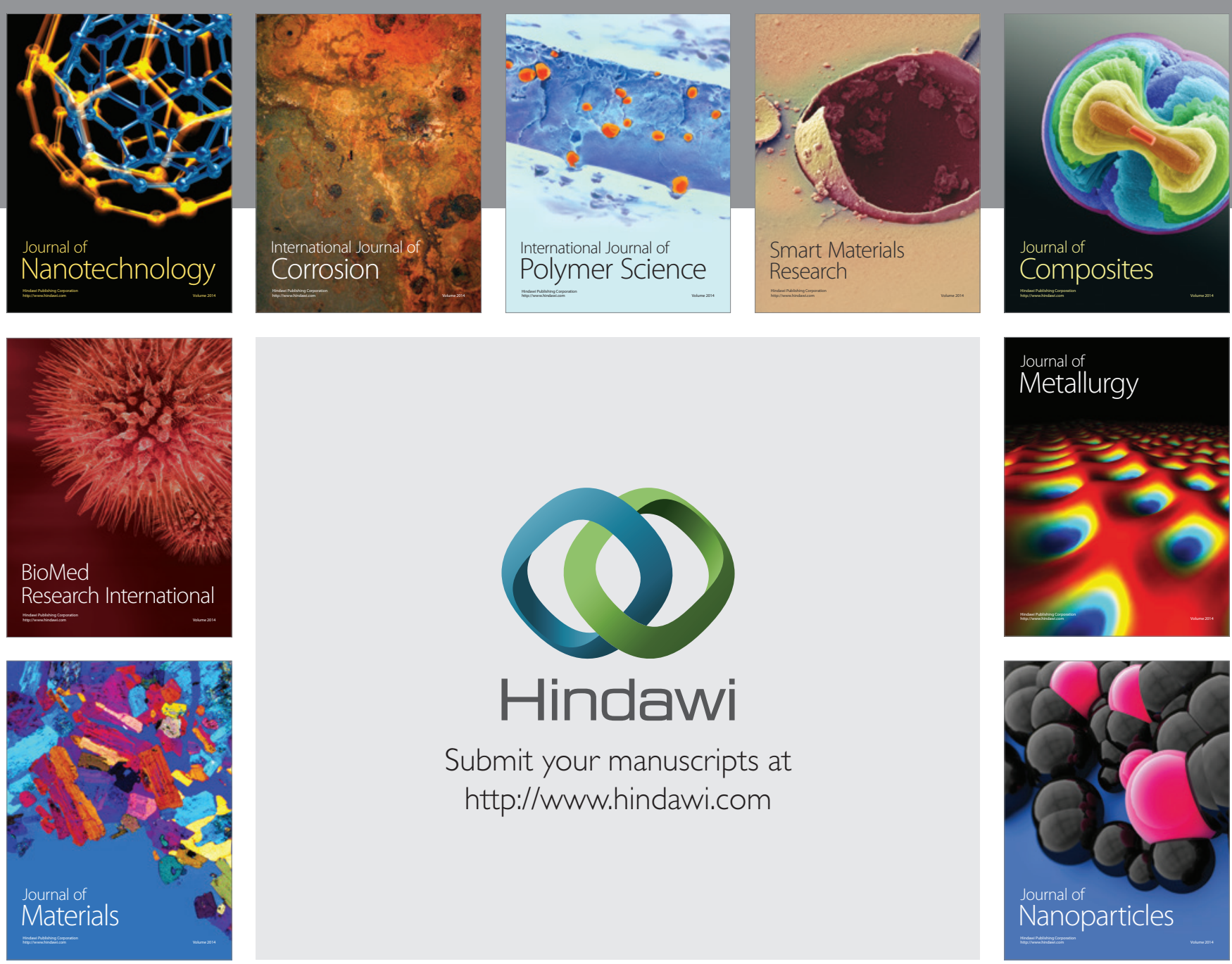

Submit your manuscripts at http://www.hindawi.com
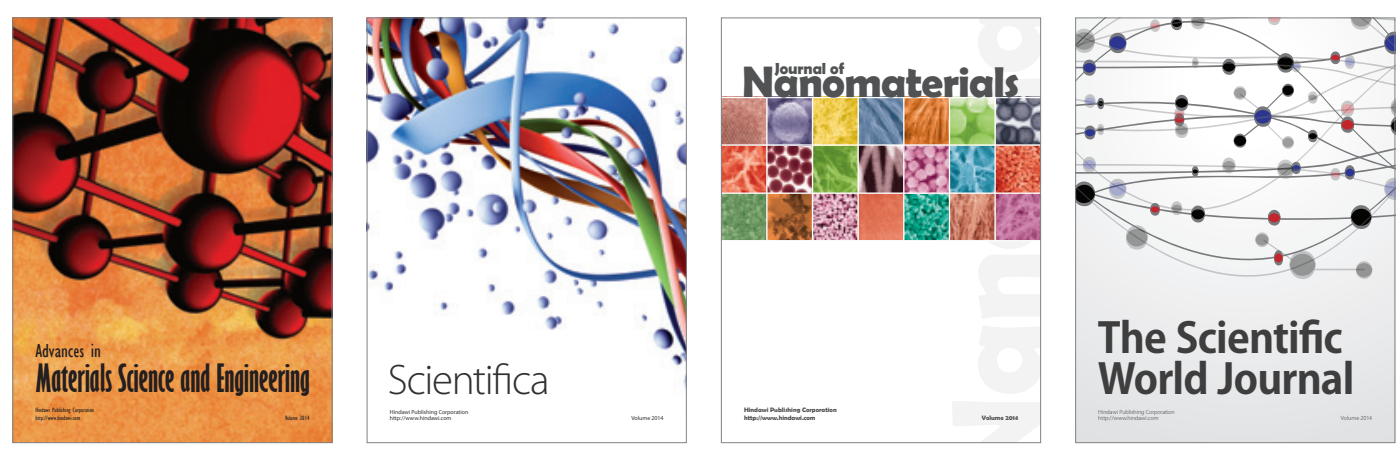

\section{The Scientific World Journal}
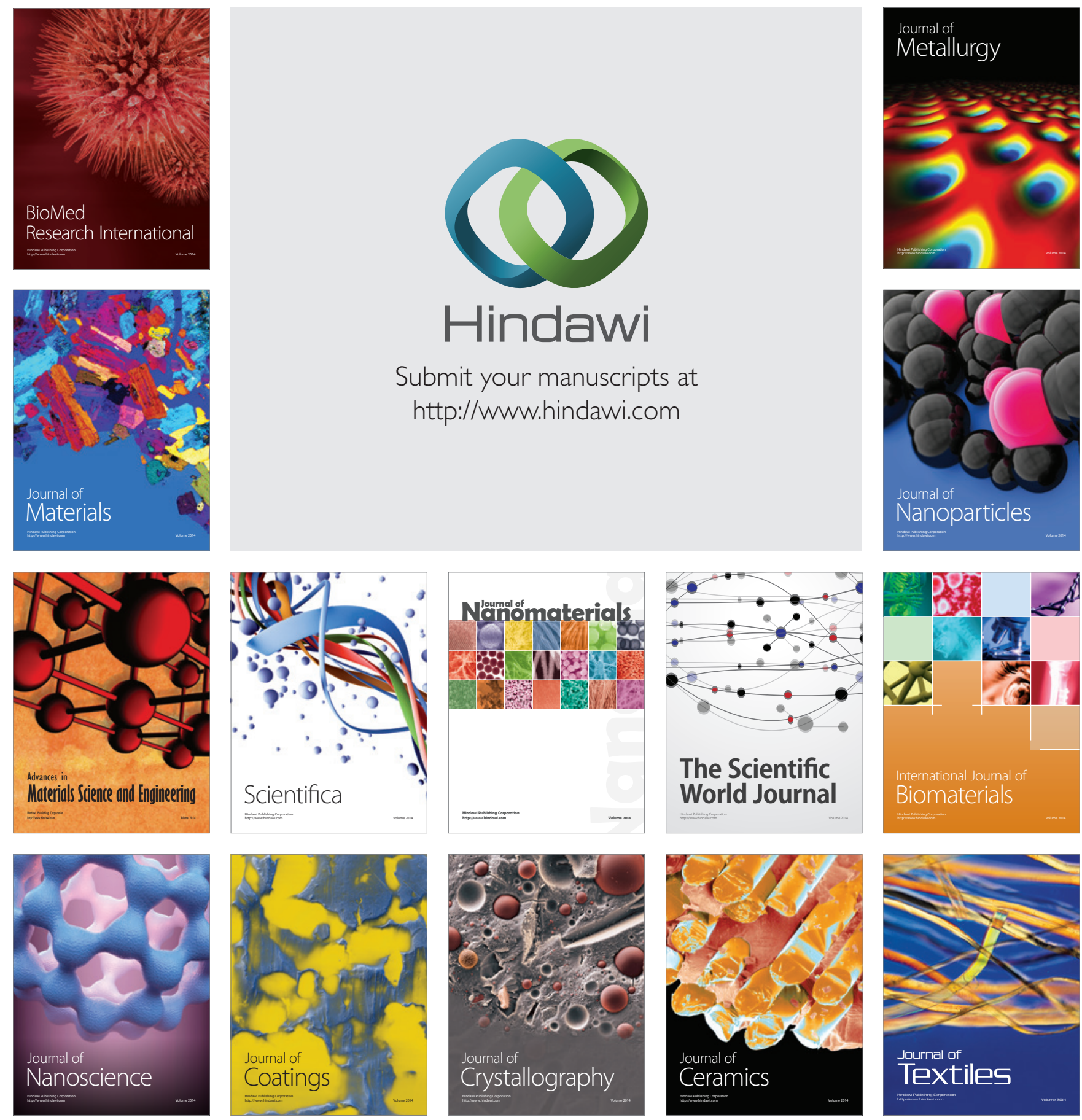